\title{
On stethoscopes, patient records, artificial intelligence, and zettabytes: A glimpse into the future of digital medicine in Mexico
}

\author{
Sobre estetoscopios, expedientes clínicos, inteligencia artificial y zettabytes: una mirada \\ al futuro de la medicina digital en México
}

\author{
Diego Araiza-Garaygordobil' *, Antonio Jordán-Ríos², Carlos Sierra-Fernández³, and \\ Luis E. Juárez-Orozco ${ }^{4,5}$
}

${ }^{1}$ Coronary and Emergency Unit; ${ }^{2}$ Department of Echocardiography; ${ }^{3}$ Teaching Directorate, Instituto Nacional de Cardiología Ignacio Chávez, Mexico City, Mexico; ${ }^{4}$ Artificial Intelligence in Cardiology, Department of Cardiology, University of Groningen, University Medical Center Groningen, Groningen, The Netherlands; ${ }^{5}$ Artificial Intelligence in Cardiovascular Research, Turku PET Centre, University of Turku and Turku University Hospital, Turku, Finland

\begin{abstract}
Science and technology are modifying medicine at a dizzying pace. Although access in our country to the benefits of innovations in the area of devices, data storage and artificial intelligence are still very restricted, the advance of digital medicine offers the opportunity to solve some of the biggest problems faced by medical practice and public health in Mexico. The potential areas where digital medicine can be disruptive are accessibility to quality medical care, centralization of specialties in large cities, dehumanization of medical treatment, lack of resources to access evidence-supported treatments, and among others. This review presents some of the advances that are guiding the new revolution in medicine, discusses the potential barriers to implementation, and suggest crucial elements for the path of incorporation of digital medicine in Mexico.
\end{abstract}

Key words: Digital medicine. Mexico. Cardiology. Digital health.

\section{Resumen}

La ciencia y la tecnología han modificado la medicina a un ritmo vertiginoso. Si bien el acceso en México a los beneficios de las innovaciones en el área de dispositivos, almacenamiento de datos e inteligencia artificial aún es muy restringido, el avance de la medicina digital ofrece la oportunidad de solventar algunos de los problemas más grandes que enfrenta la práctica médica y la salud pública en este país. Las potenciales áreas en las que la medicina digital puede resultar innovadora son la accesibilidad a cuidados médicos de calidad, la centralización de las especialidades en grandes urbes, la deshumanización del trato médico, la falta de recursos para acceder a tratamientos avalados por evidencia, entre otros. Esta revisión presenta algunos de los avances que guían la nueva revolución en la medicina, revisa el potencial y las posibles barreras para su aplicación, además de sugerir elementos cruciales para el trayecto de incorporación de la medicina digital en México.

Palabras clave: Medicina digital. México. Cardiología. Salud digital.

Correspondence:

*Diego Araiza-Garaygordobil

E-mail: dargaray@gmail.com
Available online: 04-09-2020 Arch Cardiol Mex (Eng). 2020;90(2):177-182 www.archivoscardiologia.com 2604-7063 / ๑ 2020 Instituto Nacional de Cardiología Ignacio Chávez. Published by Permanyer. This is an open access article under the CC BY-NC-ND license (http://creativecommons.org/licenses/by-nc-nd/4.0/). 


\section{Introduction}

Medicine and technological development have kept a close relationship and changed clinical practice at an increasingly accelerated pace. Only a few decades ago, doctors based their diagnostic determination and the corresponding treatment on clinical reasoning, by integrating the results of physical examination maneuvers and a few limited para-clinical tools ${ }^{1}$. Many times, diagnosis and treatment lacked a solid scientific basis.

At present, the range of tools that the doctor can use is wide and includes resources ranging from X-rays, electrocardiograms, and optical microscopy to genetic testing and advanced macroscopic and microscopic imaging. This transition between the "old" and the "new" medicine represents a continuous process, demarcated by current intellectual and technological achievements. This concept finds its parallel in the mathematical reasoning of derivatives (differential calculus), which communicates the point determination of sensitivity to change in a function or, in more colloquial terms, the rhythm of change of a system at a specific moment. Clinicians find themselves in a very interesting moment, since the rhythm of changes in science, and therefore in medicine, rush in an accelerated way and sometimes make it difficult keeping up with the updating rhythm with regard to emerging achievements, especially in health institutions with high demand and patient flow where time is vital and scarce.

Consequently, this review aims to: (a) present some of the advances that have made the concept of digital medicine a relevant and increasingly tangible topic, (b) comment on their emergence and importance in the horizon of development in Mexico in terms of their potential and challenges, and (c) suggest the way to consider their incorporation in this country.

\section{New technologies, artificial intelligence (Al), and digital medicine}

New medicine includes not only the information contained in electronic patient records or obtained through advanced clinical studies but also data extracted from various less traditional but considerably wider sources, including the internet of things, "big data," biosensors (such as watches and sport sensors and smartphones), and specialized devices (such as heart rate monitors, implantable pacemakers, and interstitial glucose monitors; Fig. 1). In 2020, the data generated by these different sources will reach more than 400 zettabytes $^{2}$

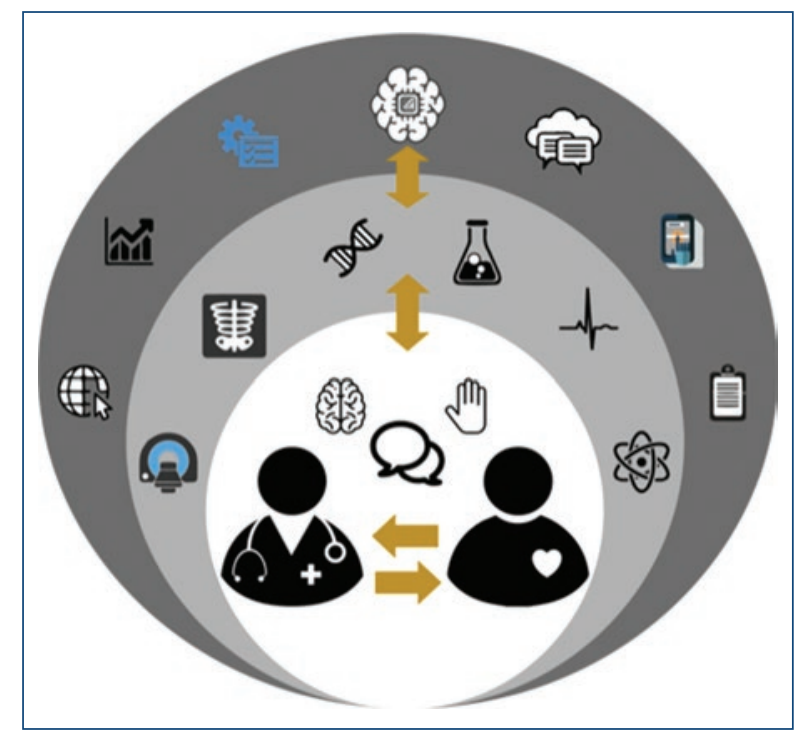

Figure 1. Evolution of the medical paradigm. Representation of the elements present in medicine for establishing an adequate interpersonal relationship, diagnosis, and prognosis. The concentric areas (white, light gray, and dark gray) contain the respective icons of traditional (interrogation, physical examination, and clinical reasoning), para-clinical (laboratory, imaging, molecular, and genetic studies), and digital components (electronic patient records, internet of things, biosensors, big data, artificial intelligence, apps, social networks, etc.) that are brought together in modern medicine. The arrows indicate the flow of information.

(equivalent to $10^{21}$ bytes or 1 trillion gigabytes) per year. Moore's law ${ }^{3}$ is still current and suggests that technological progression in terms of complexity and capacity of integrated circuits almost doubles every 2 years, i.e., at an exponential rate. To conceptualize such dimensions and behavior, consider the fact that $90 \%$ of storable information that has been generated in the history of humanity has emerged in the previous 2 years since 6 years ago (according to this logarithmic behavior) ${ }^{4}$.

At the same time, the range of apps (software) dedicated to the handling, storage, and interpretation of these data is virtually endless and has been expanded as a result of the above-mentioned patient digitization process. The need to explore and integrate large numbers of variables and data has paved the way for the recent reemergence of $\mathrm{Al}$. The new era of $\mathrm{Al}$ is based on the application of machine learning algorithms ${ }^{5}$. These algorithms are characterized by their capacity to explore, identify, and use non-linear complex dependences across multiple rounds of data exposure to optimize tasks such as image classification and effects' 
prediction. These advances result from the historical convergence of three necessary factors: capacity to store large amounts of data, new parallel processors, and the existence of intrinsically complex problems in medicine ${ }^{6}$. This means that, only until this decade, the analytic capacity of systems has turned them into extremely useful tools that in some time will be able to operate in medical settings where repetition can be avoided while human supervision can be maintained, which maximizes the benefit and personalization for patients?

Digital medicine can be conceptualized as the convergence of the storage of the large quantity of data that can be obtained from patients (genetic, demographic, and clinical), and generated by smart devices, and of their analysis with the purpose to facilitate and personalize prevention, detection, and treatment of diseases. At the same time, digital medicine includes the incorporation of telecommunication technologies and support to expand patient access to information and quality care, one of the central goals of public health ${ }^{8}$. The effect of digital era on health becomes significant because it offers the possibility of empowering the patient for having better control, measurement, follow-up, and analysis of different variables of daily relevance for his health in general, or for a specific condition; digital medicine can also improve public health system efficiency, given that it allows providing personalized medical care according to the digital measurements of the patient him/herself.

Similarly, it has the capacity to spread and expand the area of responsibilities in the care of health. Using smart phones as a central axis, each individual can generate his/her own data and participate more in his/ her own care. Furthermore, when considering the use of new imaging techniques, portable laboratories, digital medical testing, and telemedicine, it is clear that there is a large variety of transformative technologies that have founded a new paradigm in health systems.

\section{What is the potential of digital medicine incorporation in Mexico?}

Mexico is a country where health inequity is a blatant problem, a representative sample of the rest of Latin America. Health challenges, in this country, as described by Narro et al. ${ }^{9}$, include the development of health services to improve markers such as life expectancy at birth and childhood mortality, inequality reduction, limited use of infrastructure and performance by the health system, training of undergraduates and postgraduates and scientific production, and the serious problem of diabetes and obesity ${ }^{10}$ as public health priorities, as well as the challenges of health administration and financing through public and private resources. In terms of accessibility and personalized care, it is usual for patients not to receive the care they need and seek. On the other hand, health-care providers find it increasingly harder to experience satisfaction with their role as clinicians and, in many countries (developed and developing); the projection of health cost increase is probably unsustainable. On this horizon, the development of new health systems that take advantage of the benefits offered by digital innovations can help to deal with these major problems in an effective, affordable, and scalable way.

A robust medical system should meet the four P's: predictive, preventive, participatory, and personalized ${ }^{11}$, and it is possible that digital medicine can support the health system transformation, without losing sight that innovation is the means to promote universal access in health. Some examples of application areas include the use of auditing systems to control the quality of healthcare through digitized reports, the use of telemedicine to improve patient access to specialty care in marginalized and remote communities, electronic record universalization to improve care continuity between different practitioners, care centers and levels, Al use for screening studies optimization, data analysis to identify diseases and generate better risk predictions, use of online education and three-dimensional digital simulation tools to improve undergraduate and postgraduate education, access to authorship-free databases and real-time communication to improve scientific productivity, and the use of digital tools for health systems tax and financial auditing.

Although these concepts may seem theoretical, today there are already multiple digital medicine apps that have demonstrated clinical usefulness, at least within the context of clinical trials. Table 1 summarizes some clinical trials with positive results in the area of digital medicine. The examples include apps and telemedicine systems to decrease adverse outcomes or improve treatment adherence in disorders such as hypertension, diabetes mellitus, heart failure, psychiatric disorders, or heart surgery procedures.

In addition to the results in terms of medical outcomes, digital medicine can help improve doctor commitment to the patient. For example, advanced speech recognition technologies (for optimizing workflow) can avoid repetitive tasks that are time-consuming for the doctor (such as patient record integration) and at the 
Table 1. Digital medicine clinical trials and tests

\begin{tabular}{|l|l|c|l|l|}
\hline Disorder & Digital intervention & $\begin{array}{c}\text { Number of } \\
\text { patients }\end{array}$ & \multicolumn{1}{|c|}{ Effects } & Reference \\
\hline Hypertension & Smartphone App RCT & 411 & Improved medication adherence & Morakowski $^{12}$ \\
\hline Diabetes & Telemedicine RCT & 321 & Improved DM2 control & Wild $^{13}$ \\
\hline Heart failure & Telemedicine RCT & 1571 & Fewer re-hospitalizations, mortality & Koheler $^{14}$ \\
\hline $\begin{array}{l}\text { Inflammatory bowel } \\
\text { disease }\end{array}$ & Telemedicine RCT & 909 & $\begin{array}{l}\text { Fewer outpatient visits and re- } \\
\text { hospitalizations }\end{array}$ & de Jong \\
\hline $\begin{array}{l}\text { Patients with } \\
\text { chronic conditions }\end{array}$ & Smartphone App RCT & 99 & Improvement in medication adherence & Mira \\
\hline Type 1 diabetes & Smartphone App RCT & 72 & Blood glucose control improvement & Kirwan \\
\hline Alcohol dependence & $\begin{array}{l}\text { Videogame + cognitive RCT training } \\
\text { vs. conventional treatment }\end{array}$ & 68 & Better cognitive function for active arm & Gamito \\
\hline Heart operation & $\begin{array}{l}\text { Mobile application to record } \\
\text { patient-referred outcomes: case } \\
\text { series }\end{array}$ & 1418 & $\begin{array}{l}\text { Patient-derived information able } \\
\text { to predict hospital stay and independent } \\
\text { discharge after heart operation }\end{array}$ & Cook \\
\hline
\end{tabular}

The table summarizes the design and results of different digital medicine trials on various disorders. RCT: randomized clinical trial.

same time allow greater attention and quality to be given to the doctor-patient relationship ${ }^{20}$. Data collected from these conversations could be used not only to complete the records but also to guide the next generation of research in matters of joint decisions, informed consent, implicit and explicit biases, and provide the clinician with feedback on the consultations he/she provides to optimize satisfaction of both elements in this relationship.

\section{What are the barriers to digital medicine application in Mexico?}

The most important challenges for digital medicine incorporation in Mexico can be organized in two main axis (although this is not intended to be a comprehensive list): on one hand, the allocation of economic resources for the development and cost of the necessary infrastructure, and on the other hand, acceptance of technology and its new analytical methods by target groups.

It is clear from experience in other countries that the investment to develop a sustainable system that enables the development of digital medicine is considerable. For example, in 2017, the Netherlands invested more than 14 billion euros, which is equal to $1.97 \%$ of its gross domestic product (GDP), in research and development and, as a remarkable aspect; these resources come from a balance between public and private resources. At the same time, that country has focused its approach to large-scale application of health digitization $^{21}$, which requires data storage and processing centers, biobanks and information systems in hospitals and care centers, as well as considerable human capital to make them operational. The goal is to facilitate continuous data exchange in areas of medical research and health.

In Mexico, the above-mentioned GDP percentage still remains under $1 \%$. However, initiating specific maneuvers that guarantee a satisfactory transition toward health systems that incorporate digital medicine in areas where the largest benefits are demonstrated is possible. One of them is investment in biobanks and population-based studies that allow the characterization of the health-disease binomial in the Mexican population to guarantee the personalization degree that will be necessary in the future of medical care. Another area of relevance is consolidation of data processing and bioinformatics centers that support the structuring and access to data generated by the aforementioned research initiatives. These maneuvers open the scenery for advanced analyses (e.g., through Al) that reflect the larger benefit to population health and thus for health economics. As available scientific evidence with regard to digital medicine-derived resources increases, regional and national health systems will have to confront the fact of health-care current model unviability.

As for new technology acceptance trends, although there are good reasons whereby a smooth transition 
can be expected for more recent generations (e.g., millennials and generation $\mathrm{Z}$ ), who have been born in an era in which internet access has progressively become the rule and not the exception; the population that most uses portable devices in Mexico is, paradoxically, the group that needs them the least (privileged groups, people with a higher educational level and with more economic resources). In this sense, it will be of crucial importance encouraging efforts to ensure access to resources such as internet, computers, portable electronic devices and, ultimately, biosensors and other devices focusing on excluded populations.

Furthermore, one of the biggest obstacles faced by scientific and technological advancement is, sometimes, the intrinsic phenomenon of resistance to change by practicing clinicians. This psychological trend can be especially deleterious in the field of health sciences, where some degree of uncertainty is ubiquitous, but frequently this is obscured in the traditionalist discourse. The use of new technologies and analytical developments does not mean abandoning the clinical method: inspection, palpation, percussion and auscultation, much less condemning René Laënnec famous invention, the stethoscope, to death, but exercising curiosity and the conviction that has driven great scientists to modify paradigms in pursuit of the development of humanity, with an innovative spirit and always alert to possible risks. The interaction of both methods must coexist every day in medical care for all patients. Clearly, these innovations only can provide maximum benefits inasmuch as doctors and their patients can consolidate their relationship to achieve their mutual goal in this new era of medicine.

\section{How to reach the digital medicine era in Mexico?}

The fundamental elements for starting the transition to the digital era are clear: enough maturity of information technology, enough population with smartphones (73.5\%, according to the National Institute of Statistics, Geography and Informatics, INEGI [Instituto Nacional de Estadística, Geografía e Informática] ${ }^{22}$, presence of broadband, social, labor and personal networks, access to "cloud"-based platforms and presence of some servers that can host information, cyber security, and legislation for data privacy protection, and willing and increasingly trained medical personnel for its use.

Digital era full penetration requires direct collaboration of private with public sector. The former, through its inherent solvency and access to innovative

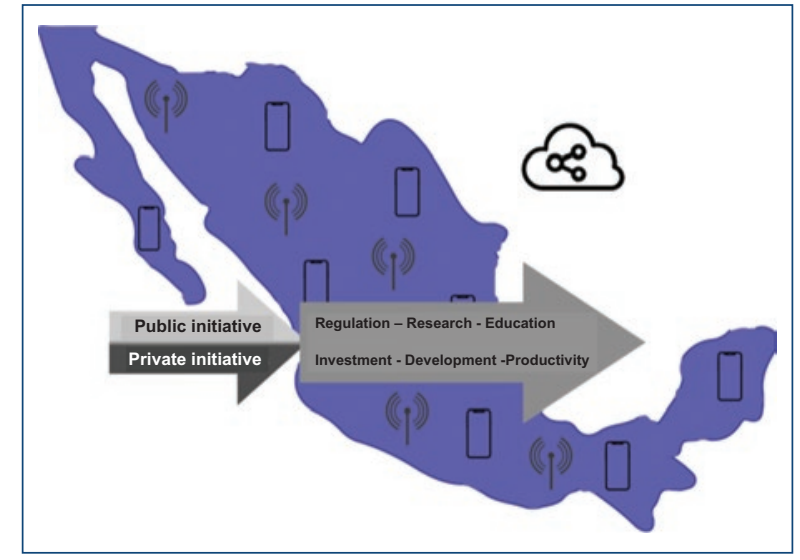

Figure 2. Depiction of the elements that can facilitate the emergence and sustainability of digital medicine in Mexico. Static elements are demonstrated in the territory and dynamic elements in the arrows.

technology resources that make incorporation of technology to the health sector viable. The latter, through a correct and agile regulation of new resources, specifically before the Federal Commission for the Protection against Sanitary Risks (COFEPRIS - Comisión Federal para la Protección contra Riesgos Sanitarios). During the first Mexican Digital Health Forum, the commissioner for sanitary risks, Julio Sánchez y Tepoz declared: "we have developed the legal and regulatory framework for medical devices, which includes a wide variety of digital devices. This has allowed a better use of financial resources, and we have also made the authorization process of such medical devices more efficient. That is the way in which we contribute and support the transition of Mexico to full digital healthcare"16.

Accessing the digital age in Mexico would not be enough without incorporating the concepts of digital medicine since medical training. The National Autonomous University of Mexico, for example, not only has high-tech medical simulators since more than one decade ago but also has recently incorporated new technologies such as virtual reality and augmented reality to the classroom of training physicians, aimed at teaching knowledge in anatomy and physiology, but specially at the acquisition of clinical thought and judgment for solving health problems (Fig. 2 shows the factors that would facilitate the establishment of digital medicine in Mexico). Examples of the above are the digital education systems visible body, anatomy learning, body interacts, and among others. In this same sense, constant updating at different degrees of medical specialization and in various clinical care areas will 
be crucial to promote the visibility of digital medicine and therefore facilitate its expansion through the health system.

\section{Conclusions}

The emerging concept of digital medicine comprises the use of new technologies and advanced analytical methods, such as Al, to improve the practice of medicine, clinical outcomes, and the doctor-patient relationship. These advances offer the opportunity to optimize personalization and quality of medical care and might lessen health system problems in Mexico and other Latin American countries. To stimulate the transition to the era of digital medicine in this country, it is necessary to have the collaboration between the private and public sectors, to incorporate the concepts that underlie digital medicine in medical teaching and maximize the promotion and visualization of these innovations in Mexico. For the authors, it is clear that digital medicine will transform health systems in Mexico and the world in the coming years ${ }^{23}$.

\section{Funding}

There was no funding for the preparation of this study.

\section{Conflicts of interest}

None.

\section{Ethical disclosures}

Protection of people and animals. The authors declare that no experiments on humans or animals were performed for this investigation.

Confidentiality of data. The authors declare that no patient data appear in this article.

Right to privacy and informed consent. The authors declare that no patient data appear in this article.

\section{References}

1. Ellis LB, Harken DE. Mitral stenosis, clinico-physiologic correlations, with particular reference to surgical intervention. Trans Am Clin Climatol Assoc. 1948;60:59-70.
2. Scientific American. [2017] USA: www.scientificamerican.com [accessed 22.09.2019]. Available from: https://www.scientificamerican.com/article/ dna-data-storage-is-closer-than-you-think/)

3. Moore G [2006]. Chapter 7: Moore's law at 40. In Brock D [ed.]. Understanding Moore's law: four decades of innovation. Chemical Heritage Foundation. pp. 67-84)

4. Science Daily. [2017] USA: www.sciencedaily.com [accessed 22.09.2019]. Available from: https:/www.sciencedaily.com/releases/ 2013/ 05/ 130522085217.html

5. Juárez-Orozco LE. Machine learning in the evaluation of myocardial ischemia through nuclear cardiology. Curr Cardiovasc Imaging Rep. 2019;12(2):5.

6. Juárez-Orozco LE. The machine learning horizon in cardiac hybrid imag- ing. Eur J Hybrid Imaging 2018;2(1):15.

7. Krittanawong $C$. Artificial intelligence in precision cardiovascular medicine. J Am Coll Cardiol. 2017;69(21):2657-2664.

8. Steinhubl SR, Topol EJ. Digital medicine, on its way to being just plain medicine. NPJ Dig Med. 2018;20175.

9. Narro-Robles J, Zepeda-Tena C. La salud en México: antiguos y nacientes desafíos. Un examen actualizado. Gac Med Mex. 2012;148:390-9.

10. Medina C. Evidence of increasing sedentarism in Mexico City during the last decade: sitting time prevalence, trends, and associations with obesity and diabetes. PLoS One. 2017;12(12):e0188518.

11. Sagner M, McNeil $A$, Arena R. El próximo capítulo: el futuro de la asistencia sanitaria y de las intervenciones del estilo de vida. En: Egger G, Binns A, Rösnner S, Sagner M. Medicina del estilo de vida: hábitos, entorno, prevención y promoción de la salud. $3^{\mathrm{a}}$ ed. Barcelona: Elsevier, 2017:348-50.

12. Morawski K, Ghazinouri R, Krumme A, Lauffenburger JC, Lu Z, Durfee E, et al. Association of a smartphone application with medication adherence and blood pressure control: The MedISAFE-BP Randomized Clinical Trial. JAMA Intern Med. 2018;178:802-9.

13. Wild SH, Hanley J, Lewis SC, McKnight JA, McCloughan LB, Padfield PL, et al. Supported telemonitoring and glycemic control in people with type 2 diabetes: The Telescot Diabetes Pragmatic Multicenter Randomized Controlled Trial. PLoS Med 2016; 1002098

14. Koehler F, Koehler K, Deckwart O, Prescher S, Wegscheider K, Kirwan BA, et al. Efficacy of telemedical interventional management in patients with heart failure (TIM-HF2): a randomised, controlled, parallel-group, unmasked trial. Lancet 2018;392:1047-57.

15. de Jong MJ, van der Meulen-de Jong AE, Romberg-Camps MJ, Becx MC, Maljaars JP, Cilissen M, et al. Telemedicine for management of inflammatory bowel disease (mylBDcoach): a pragmatic, multicentre, randomised controlled trial. Lancet 2017;390:959-68.

16. Mira JJ, Navarro I, Botella F, Borrás F, Nuño-Solinís R, Orozco D, et al. A Spanish pillbox app for elderly patients taking multiple medications: randomized controlled trial. J Med Internet Res. 2014;6:e99.

17. Kirwan M, Vandelanotte C, Fenning A, Duncan MJ. Diabetes self-management smartphone application for adults with type 1 diabetes: randomized controlled trial. J Med Internet Res. 2013;15:e235.

18. Gamito P, Oliveira J, Lopes P, Brito R, Morais D, Silva D, et al. Executive functioning in alcoholics following an mHealth cognitive stimulation program: randomized controlled trial. J Med Internet Res. 2014;16:e102.

19. Cook DJ, Manning DM, Holland DE, Prinsen SK, Rudzik SD, Roger VL, et al. Patient engagement and reported outcomes in surgical recovery: effectiveness of an e-health platform. J Am Coll Surg. 2013;217:648-55.

20. Dela Cruz JE, Shabosky JC, Albrecht M, Clark TR, Milbrandt JC, Markwell SJ, et al. Typed versus voice recognition for data entry in electronic health records: emergency physician time use and interruptions. West J Emerg Med. 2014;15:541-7.

21. The digital health market in the Netherlands and Switzerland. Embassy of the Kingdom of the Netherlands in Berne, Switzerland 2019. Available from: https://www.rvo.nl/sites/default/files/2019/03/the-digital-health-market-in-the-netherlands-and-switzerland.pdf

22. Instituto Nacional de Estadística, Geografía e Informática. Encuesta sobre Disponibilidad y Uso de Tecnologías de la Información y la Comunicación en los Hogares. [2017] México: www.inegi.org.mx [accessed 22.09.2019]. Available from: https://www.inegi.org.mx contenidos/saladeprensa/boletines/2019/OtrTemEcon/ENDUTIH_2018.pdf

23. Rojas JR. "México pasa a la salud digital para mejorar la atención médica". Blasting news. [2018] México: [accessed 22.09.2019]. https://mx. blastingnews.com/tecnologia/2018/03/mexico-pasa-a-la-salud-digital-para-mejorar-la-atencion-medica-002431681.html 